\title{
Results on efficacy and safety of cancer treatment with or without tumor necrosis factor-related apoptosis-inducing ligand-related agents: A meta-analysis
}

\author{
SHAOXING SUN ${ }^{1 *}$, ZONGHUAN LI $^{1 *}$, LI SUN $^{1 *}$, CHUNXU YANG $^{1}$, \\ ZIJIE MEI ${ }^{1}$, WEN OUYANG ${ }^{1}$, BO YANG ${ }^{1}$ and CONGHUA XIE ${ }^{1,2}$ \\ ${ }^{1}$ Department of Radiation and Medical Oncology; ${ }^{2}$ Hubei Key Laboratory of Tumor Biological Behaviors, \\ Zhongnan Hospital of Wuhan University, Wuhan, Hubei 430071, P.R. China
}

Received October 8, 2013; Accepted January 21, 2014

DOI: $10.3892 / \mathrm{mco} .2014 .261$

\begin{abstract}
This meta-analysis aimed to evaluate the currently available evidence on the efficacy and safety of cancer treatment with or without tumor necrosis factor-related apoptosis-inducing ligand (TRAIL)-related agents. We conducted a systematic search through Medline, Cochrane Library and EMBASE electronic databases and manually searched the Journal of Clinical Oncology to identify randomized controlled trials (RCTs) conducted between 1995 and 2013 comparing the efficacy and safety results of cancer treatment with and without TRAIL-related agents. The methodological quality of the included RCTs was assessed by the Cochrane Risk of Bias assessment tool. The outcome measurements included objective response rate (ORR), clinical benefit rate (CBR)/disease control rate (DCR) and adverse events (AEs). The relevant data were analyzed using Review Manager 5.2 software. Grading of Recommendations Assessment Development and Evaluation was used to assess the quality of evidence and grade of recommendation. Four RCTs, including a total of 596 patients, were ultimately selected and analyzed. There were no statistically significant differences among the 4 RCTs regarding ORR [relative risk $(\mathrm{RR})=0.92$, 95\% confidence interval (CI): 0.73-1.15, $\mathrm{P}=0.45], \mathrm{CBR} / \mathrm{DCR}(\mathrm{RR}=0.92$, 95\% CI: 0.81-1.05, $\mathrm{P}=0.21$ ), progression-free survival [hazard ratio $(\mathrm{HR})=0.89,95 \% \mathrm{CI}: 0.75-1.05, \mathrm{P}=0.16]$, overall survival (HR=0.90, 95\% CI: $0.74-1.09, \mathrm{P}=0.27)$, number of patients with any AEs ( $R R=0.99,95 \%$ CI: 0.96-1.03, $\mathrm{P}=0.77)$, number
\end{abstract}

Correspondence to: Professor Conghua Xie, Department of Radiation and Medical Oncology, Zhongnan Hospital of Wuhan University, 169 Donghu Road, Wuchang District, Wuhan, Hubei 430071, P.R. China

E-mail: chxie_65@hotmail.com

${ }^{*}$ Contributed equally

Key words: tumor necrosis factor-related apoptosis-inducing ligand, cancer, efficacy, safety, randomized controlled trials, meta-analysis of patients with any severe AEs (RR=0.95, 95\% CI: 0.78-1.55, $\mathrm{P}=0.58)$, number of patients with $\geq$ grade 3 AEs $(\mathrm{RR}=1.13$, 95\% CI: 0.93-1.38, $\mathrm{P}=0.22)$ and number of fatal AEs $(\mathrm{RR}=1.14$, 95\% CI: 0.71-1.81, $\mathrm{P}=0.59$ ). The quality of evidence was considered to be moderate and the recommendation grades were weak. In conclusion, the benefits of TRAIL-related agents in the treatment of cancer patients remain uncertain and further clinical trials are required.

\section{Introduction}

Cancer is a major public health concern worldwide and has been ranked first in the disease spectrum. A total of 1,638,910 new cancer cases and 577,190 cancer deaths were projected to occur in the United States in 2012 (1). Despite significant advances in cancer treatment strategies, surgical resection, chemotherapy and radiotherapy remain the primary methods for cancer treatment. However, the conventional first- or second-line chemotherapy treatments, although they may be efficient, they are often associated with toxicity, occasionally so severe that requires treatment discontinuation. Furthermore, following a long period of repeated treatment, tumor resistance may also develop. Therefore, novel effective agents, with an acceptable toxicity profile, are urgently required.

Tumor necrosis factor-related apoptosis-inducing ligand (TRAIL), also referred to as Apo2L, was first discovered in 1995. It was observed that full-length TRAIL is expressed on the cell surface and picomolar concentrations of soluble TRAIL rapidly induce apoptosis in a wide variety of transformed cell lines of diverse origin, without affecting normal cells $(2,3)$. TRAIL is a type II membrane protein consisting of 281 amino acids. TRAIL may bind to the death receptor (DR) 4 or DR5, leading to the transduction of an apoptotic signal, which triggers transformed cell death (4-8). However, normal cells survive due to the function of the decay receptors, (DcR)1 and DcR2, which are able to bind TRAIL without apoptotic signal transduction, due to the absence of a death domain $(5,7)$. This suggests that TRAIL may be a promising strategy for cancer treatment and may result in the development of cancer therapies that target this apoptotic pathway. The TRAIL apoptotic pathway has been targeted by at least 
two approaches: the recombinant human TRAIL (rhTRAIL) ligand and its agonistic antibodies against DR4 and DR5 (9). In this study, we applied the term 'TRAIL-related agents' to refer to this type of drug.

Several randomized controlled trials (RCTs) were conducted over the last few years and the majority of the results did not support the addition of TRAIL-related agents to cancer treatment regimens. However, to the best of our knowledge, no systematic review or meta-analysis of the currently available evidence has been conducted thus far. This meta-analysis aimed to investigate the safety and efficacy of TRAIL-related agents.

\section{Materials and methods}

Study design and search strategy. All the published RCTs comparing TRAIL-related agents with other therapies for cancer treatment were independently searched for by two authors (Sun S and Sun L). Other therapies included drugs that had been applied as first- or second-line cancer treatment. Medline, the Cochrane Library and EMBASE databases were searched. We also performed a manual search of the reference abstracts in the Journal of Clinical Oncology for the American Society of Clinical Oncology, in order to obtain the latest data. RCTs were included if they were conducted between 1995 and May 31, 2013. The publication language was limited to English. The following key words were used to search PubMed: 'TNF-related apoptosis-inducing ligand', 'tumor necrosis factor-related apoptosis-inducing ligand', 'TRAIL', 'Apo2L', 'rhTRAIL', 'rhApo2L', 'HGS-ETR1', 'HGS-ETR2', 'Apomab', 'TRA-8', 'CS-1008', 'AMG 655', 'LBY135', 'PRO95780', ‘drozitumab', 'HGS-TR2J', 'KMTR-2', 'lexatumumab', 'conatumumab', 'tigatuzumab', 'dulanermin', 'mapatumumab', 'death receptor 4', 'DR4', 'death receptor 5', 'DR5', 'neoplasms', 'neoplasm', 'tumor', 'tumour', 'cancer', 'clinical trial' and 'random controlled trial'.

Inclusion and exclusion criteria. Only the RCTs comparing TRAIL-related agents with traditional therapies for cancer treatment were included in this study, regardless of whether they were blinded.

Inclusion criteria of the original articles: i) cancer patients with measurable or evaluable disease that had been histologically or cytologically confirmed; ii) patients aged $\geq 18$ years, without gender or race restrictions; iii) Eastern Cooperative Oncology Group performance status 0-2; iv) no contraindication of chemotherapy with regards to hepatic, renal and hematopoietic function; v) life expectancy of $\geq 3$ months; vi) efficacy assessed by the Response Evaluation Criteria in Solid Tumors; vii) no untreated or unstable central nervous system metastases; viii) no prior chemotherapy or radiotherapy (except adjuvant chemotherapy within 1 year of enrollment); and ix) patients provided written informed consent.

Interventions and comparisons: i) the articles investigated cancer treatment and included a complete protocol; ii) TRAIL-related agents were used as an intervention, without restriction of dose and usage methods; and iii) other chemotherapies, including targeted therapy, were used as control.

Outcome measurements: i) complete tumor response and survival data; and ii) complete adverse event (AE) data.
Exclusion criteria: i) retrospective, cohort, clinically controlled or any type of study other than RCT; ii) study not published in English; iii) study published without effective reporting of the primary results or adequate data for a meta-analysis and the missing data were not available after contacting the authors; iv) only the abstract was available (no full text); and v) the efficacy data were not accurate and clear.

Study identification. Two reviewers (Sun S and Sun L) independently screened the titles of all the retrieved articles. We first reviewed the abstract of the articles that were relevant to the topic. The full text was then obtained through different approaches to retrieve more information on the selected clinical trials. A third reviewer (Xie C) was consulted for the final decision in case of any disagreement on eligibility between the first two reviewers.

Data extraction. The extracted data consisted of two parts: i) general information (study type, time, location, number of cases in each group and gender ratio); and ii) data for the meta-analysis (tumor response, survival and AEs). Two reviewers (Sun $\mathrm{S}$ and $\mathrm{Li} \mathrm{Z}$ ) participated in the extraction of data from all the eligible RCTs. The third reviewer (Xie C) was consulted if necessary.

Study assessment. The studies were independently assessed by two reviewers (Sun S and Li Z) . A third reviewer (Xie C) was consulted in case of any disagreement. The study assessment included: i) Assessing the risk of bias. The Cochrane Collaboration's tool for assessing the risk of bias was used (10), which consists of 6 items. Each question was answered with yes (low risk of bias), no (high risk of bias) or unclear (unclear risk of bias). ii) Evidence quality and recommended grade. Based on the outcomes of the systematic review, Grading of Recommendations Assessment Development and Evaluation (GRADE) was used to assess the quality of the evidence. The quality of the evidence for each outcome measurement falls into one of four categories: high, moderate, low and very low (11). RCTs have high-quality evidence, with 5 factors that may result in a lower rating of the quality of evidence and 3 factors that may cause an increase in the rating. The grading recommendation was described as strong (i.e., the authors were confident that the intervention with TRAIL-related agents has more advantages or disadvantages) or weak (i.e., the authors were not certain whether the intervention has more advantages or disadvantages or, regardless of the high or low quality of the evidence, they all indicated that the advantages and disadvantages were equal).

Outcomes for the meta-analysis. The outcomes considered in this meta-analysis included the objective response rate (ORR), the clinical benefit rate (CBR)/disease control rate (DCR) and AEs. ORR included complete response (CR) and partial response (PR), whereas $\mathrm{CBR} / \mathrm{DCR}$ included $\mathrm{CR}, \mathrm{PR}$ and stable disease (SD).

Statistical analysis. The meta-analysis was conducted with the Cochrane Collaboration Review Manager 5.2 software (http://tech.cochrane.org/revman). P $\leq 0.05$ was considered to indicate a statistically significant difference. 
Table I. General characteristics of the included randomized controlled trials.

\begin{tabular}{|c|c|c|c|c|}
\hline Studies (refs.) & $\begin{array}{c}\text { Sample } \\
\text { size }(T / C)\end{array}$ & $\begin{array}{l}\text { Type of } \\
\text { tumor }\end{array}$ & Intervention and comparison & Outcomes \\
\hline Soria et al (13) & $128 / 85$ & $\begin{array}{l}\text { Advanced } \\
\text { NSCLC }\end{array}$ & $\begin{array}{l}\text { Patients with squamous NSCLC and/or CNS metastases } \\
\text { received PC every } 3 \text { weeks alone }(\operatorname{arm} 1 ; n=41) \text { or with } \\
\text { dulanermin } 8 \mathrm{mg} / \mathrm{kg} \text { for } 5 \text { days }(\operatorname{arm} 2 ; \mathrm{n}=39) \text {. Patients } \\
\text { with non-squamous NSCLC received PCB alone } \\
(\operatorname{arm} 3 ; \mathrm{n}=42) \text { or with dulanermin } 8 \mathrm{mg} / \mathrm{kg} \text { for } 5 \text { days } \\
(\operatorname{arm~} 4 ; \mathrm{n}=40) \text { or } 20 \mathrm{mg} / \mathrm{kg} \text { for } 2 \text { days }(\operatorname{arm} 5 ; \mathrm{n}=41)\end{array}$ & $\begin{array}{l}\text { ORR, PFS, OS, safety, } \\
\text { pharmacodynamics } \\
\text { biomarker analysis, } \\
\text { GaINT } 14 \text { expression } \\
\text { biomarker analysis }\end{array}$ \\
\hline Demetri et al (14) & $86 / 42$ & $\begin{array}{l}\text { Metastatic } \\
\text { or locally } \\
\text { advanced } \\
\text { unresectable } \\
\text { soft tissue } \\
\text { sarcomas }\end{array}$ & $\begin{array}{l}\text { This clinical trial consists of three parts: phase I, phase II and } \\
\text { rollover. In phase II, patients were randomized }(2: 1) \text { to receive } \\
\text { doxorubicin with either double-blind conatumumab } 15 \mathrm{mg} / \mathrm{kg} \\
\text { (conatumumab-doxorubicin; } \mathrm{n}=86 \text { ) or placebo } \\
\text { (placebo-doxorubicin; } \mathrm{n}=42 \text { ) }\end{array}$ & $\begin{array}{l}\text { PFS as primary efficacy } \\
\text { variable; OS, subgroup } \\
\text { analysis of PFS } \\
\text { according to FCGR3A } \\
\text { genotype, patient- } \\
\text { reported outcomes, time } \\
\text { to response and duration } \\
\text { of response as secondary } \\
\text { efficacy variables; } \\
\text { safety, biomarker ana- } \\
\text { lysis, pharmacokinetics }\end{array}$ \\
\hline Kindler et al (15) & $41 / 42$ & $\begin{array}{l}\text { Metastatic } \\
\text { pancreatic } \\
\text { cancer }\end{array}$ & $\begin{array}{l}\text { Patients with previously untreated metastatic pancreatic } \\
\text { adenocarcinoma were randomized 1:1:1 to i.v. gemcitabine } \\
1,000 \mathrm{mg} / \mathrm{m}^{2} \text { (days } 1,8 \text { and } 15 \text { of each } 28 \text {-day cycle) } \\
\text { combined with open-label ganitumab }(12 \mathrm{mg} / \mathrm{kg} \mathrm{Q} 2 \mathrm{~W} \text {, } \\
\mathrm{n}=42) \text {, double-blind conatumumab }(10 \mathrm{mg} / \mathrm{kg} \mathrm{Q} 2 \mathrm{~W}, \\
\mathrm{n}=41) \text {, or double-blind placebo Q2W }(\mathrm{n}=42)\end{array}$ & $\begin{array}{l}\text { Survival and response, } \\
\text { safety }\end{array}$ \\
\hline Paz-Ares et al (16) & $113 / 59$ & $\begin{array}{l}\text { Advanced } \\
\text { or recurrent } \\
\text { NSCLC }\end{array}$ & $\begin{array}{l}\text { Patients (aged >18 years) with previously untreated advanced } \\
\text { or recurrent NSCLC were randomized 1:1:1 (stratified by ECOG } \\
\text { performance status and disease stage) to receive up to six } \\
3 \text {-week cycles of PC combined with conatumumab (arm } 1 \text {, } \\
3 \mathrm{mg} / \mathrm{kg} ; \operatorname{arm} 2,15 \mathrm{mg} / \mathrm{kg} \text { ) or placebo }(\operatorname{arm} 3 \text { ) every } 3 \text { weeks } \\
\text { Arm } 1, \mathrm{n}=57 ; \operatorname{arm~} 2, \mathrm{n}=56 ; \text { arm } 3, \mathrm{n}=59\end{array}$ & $\begin{array}{l}\text { PFS as primary end- } \\
\text { point, ORR, toxicity, } \\
\text { pharmacokinetics, } \\
\text { subgroup analysis of OS } \\
\text { according to FCGR3A } \\
158 \text { polymorphisms }\end{array}$ \\
\hline
\end{tabular}

T/C, trial/control; NSCLC, non-small-cell lung cancer; CNS, central nervous system; ORR, objective response rate; PFS, progression-free survival; OS, overall survival; PC, paclitaxel plus carboplatin; PCB, paclitaxel plus carboplatin and bevacizumab; i.v., intravenous; Q2W, quaque (every) 2 weeks; ECOG, Eastern Cooperative Oncology Group.

For continuous data, a weighted mean difference or standard mean difference were used in this study, both with $95 \%$ confidence intervals (CIs). For dichotomous outcomes, an odds ratio $(\mathrm{OR})$ or relative risk $(\mathrm{RR})$ were calculated as the summary statistics, both with $95 \%$ CIs. When the related data were calculated, two decimals were kept. The statistical heterogeneity was tested with the $\chi^{2}$ and $\mathrm{I}^{2}$ tests. $\mathrm{P} \geq 0.05$ and $\mathrm{I}^{2} \leq 50 \%$ were considered to indicate low statistical heterogeneity and, therefore, the fixed effects model was used. $\mathrm{P}<0.05$ and $\mathrm{I}^{2}>50 \%$ were considered to indicate high heterogeneity and the random effects model was adopted. The source of high heterogeneity was investigated by subgroup analysis based on the methodological quality after clinical heterogeneity was excluded. GRADE Pro 3.6 software was used for the GRADE assessment. Observed-expected (O-E) and its variance of progression-free survival (PFS) and overall survival (OS) were calculated with a method introduced by Tierney et al (12), assisted by the Engauge Digitizer 4.1 software (http://digitizer.sourceforge.net). A sensitivity analysis was performed by excluding studies one by one. Data input was executed by one reviewer under the supervision of a second reviewer.

\section{Results}

Search for relevant articles and general characteristics of the included RCTs. A total of 2,224 relevant articles were retrieved. The study selection process is summarized in Fig. 1. We selected 77 clinical trials that investigated TRAIL-related agents for cancer treatment, of which 73 articles were excluded as they were reference abstracts without a detailed data report or were studies other than RCTs. Two reviewers confirmed 4 RCTs (13-16) as being suitable for inclusion in this meta-analysis. The general characteristics of the eligible RCTs are summarized in Table I.

Risk of bias of the included RCTs. As shown in Figs. 2 and 3, according to the Cochrane Collaboration's tool for assessing the risk of bias, random sequence generation and allocation concealment of 3 RCTs were considered as low-risk for the proper application of the stratification strategy and randomization methods (centralized randomization). One RCT was considered to have an unclear risk of bias. One RCT was described as an open-label trial, whereas the remaining were described as double-blind trials. All the RCTs provided 


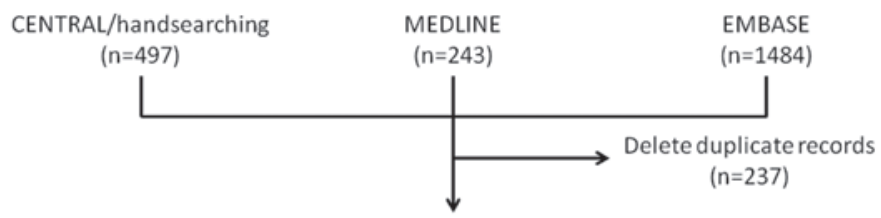

Study selection based on title and abstract for inclusion ( $n=1931$ )

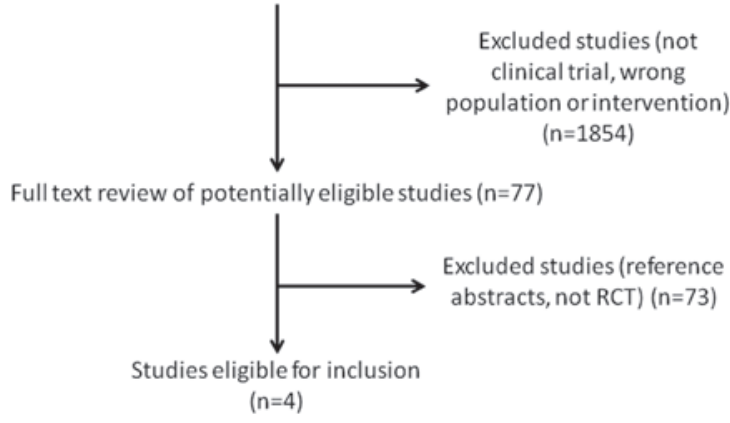

Figure 1. Flow diagram of the selection process for eligible randomized controlled trials (RCTs).

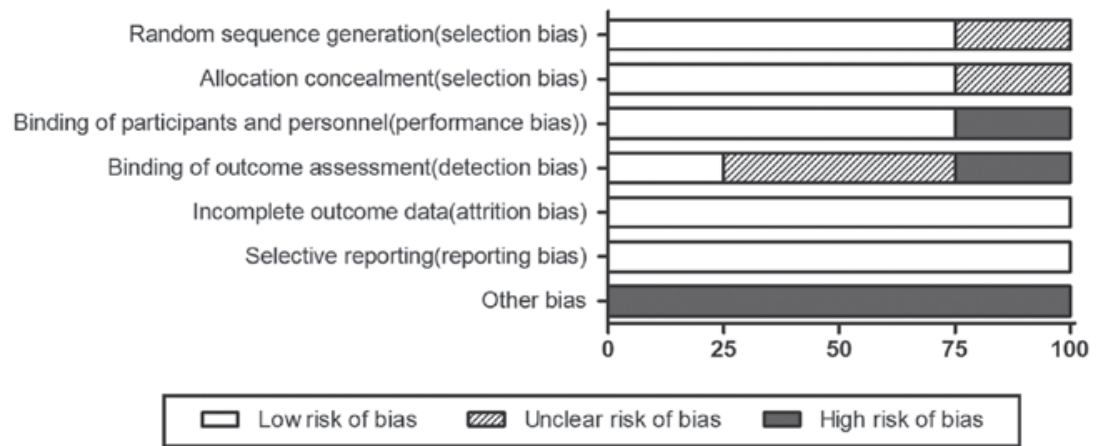

Figure 2. Risk of bias graph.

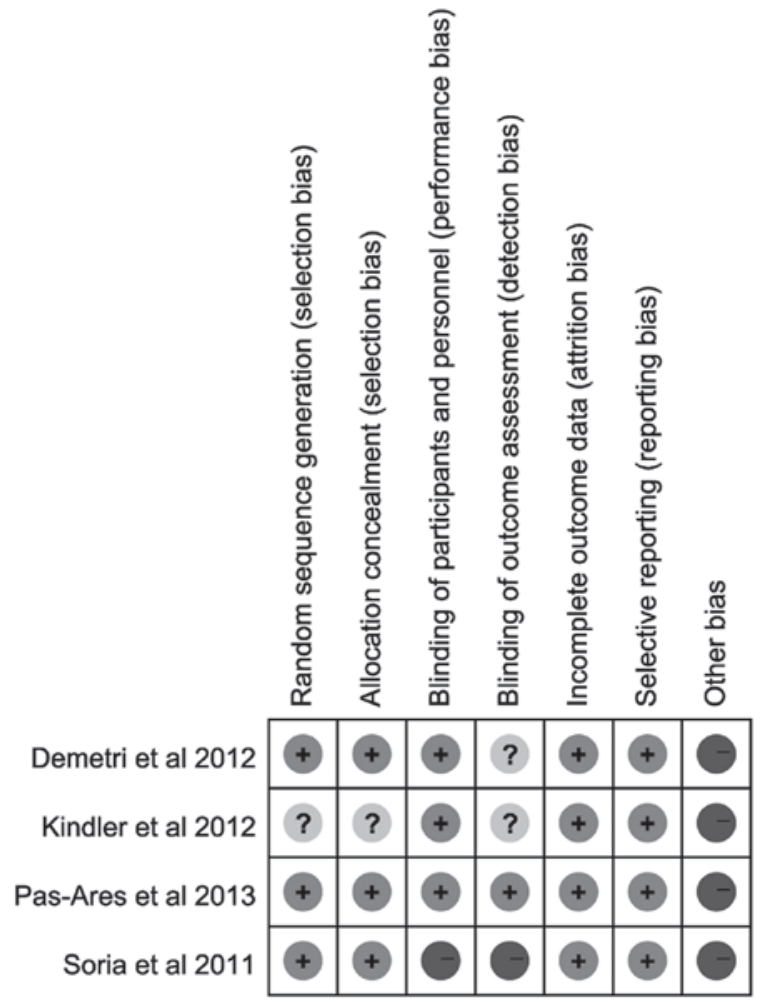

Figure 3. Summary of the risk of bias of the 4 randomized controlled trials. complete outcome measurements that were assessed in this meta-analysis. Other bias were considered as high risk, as there were clear statements of company funding.

Meta-analysis. In this meta-analysis, data from 4 RCTs were included. As the subgroup of the 4 RCTs was not consistent, we considered the subgroups as independent clinical trials and analyzed them separately. The data from Soria et al (13) were divided into three parts: i) paclitaxel plus carboplatin (PC) vs. PC + dulanermin; ii) PC and bevacizumab (PCB) vs. $\mathrm{PCB}+$ dulanermin $(8 \mathrm{mg} / \mathrm{kg})$; and iii) $\mathrm{PCB}$ vs. $\mathrm{PCB}+$ dulanermin $(20 \mathrm{mg} / \mathrm{kg})$. The data from Paz-Ares et al (16) were divided into two parts: i) $\mathrm{PC}+$ placebo vs. $\mathrm{PC}+$ conatumumab $(3 \mathrm{mg} / \mathrm{kg})$; and ii) $\mathrm{PC}+$ placebo vs. $\mathrm{PC}+$ conatumumab $(20 \mathrm{mg} / \mathrm{kg})$.

ORR. The results of the 4 included RCTs are shown in Fig. 4. There was no heterogeneity between studies $\left(\mathrm{P}=0.95, \mathrm{I}^{2}=0 \%\right)$. The results indicated that treatment with TRAIL-related agents conferred no statistically significant differences in the ORR compared to that of the control group ( $\mathrm{RR}=0.92,95 \%$ CI: 0.73-1.15, $\mathrm{P}=0.45$ ).

$C B R / D C R$. The 4 included RCTs provided CBR/DCR data and the analysis of the outcome is shown in Fig. 5. The random effects model was applied due to the median heterogeneity among the included studies $\left(\mathrm{P}=0.03, \mathrm{I}^{2}=56 \%\right)$. The 


\begin{tabular}{|c|c|c|c|c|c|c|c|c|c|}
\hline \multirow[b]{2}{*}{ Study or Subgroup } & \multicolumn{2}{|c|}{ Experimental } & \multicolumn{2}{|c|}{ Control } & \multirow{2}{*}{ Weight } & \multirow{2}{*}{$\begin{array}{l}\text { Risk Ratio } \\
\text { M-H, Fixed, } 95 \% \text { Cl }\end{array}$} & \multirow{2}{*}{\multicolumn{3}{|c|}{$\begin{array}{c}\text { Risk Ratio } \\
\text { M-H, Fixed, } 95 \% \mathrm{Cl}\end{array}$}} \\
\hline & Events & Total & Events & Total & & & & & \\
\hline George D.Demetri 2012 & 17 & 86 & 10 & 42 & $13.2 \%$ & $0.83[0.42,1.65]$ & $\longrightarrow$ & & \\
\hline H.L.Kindler 2012 & 1 & 41 & 1 & 42 & $1.0 \%$ & $1.02[0.07,15.84]$ & & & \\
\hline Jean-Charles Soria2011(1) & 16 & 42 & 16 & 41 & $16.0 \%$ & $0.98[0.57,1.68]$ & & & \\
\hline Jean-Charles Soria2011(2) & 17 & 43 & 22 & 44 & $21.4 \%$ & $0.79[0.49,1.27]$ & & & \\
\hline Jean-Charles Soria2011(3) & 17 & 43 & 22 & 44 & $21.4 \%$ & $0.79[0.49,1.27]$ & & & \\
\hline Luis Pas-Ares 2013(1) & 15 & 57 & 14 & 59 & $13.6 \%$ & $1.11[0.59,2.08]$ & & & \\
\hline Luis Pas-Ares 2013(2) & 15 & 56 & 14 & 59 & $13.4 \%$ & $1.13[0.60,2.12]$ & & & \\
\hline Total $(95 \% \mathrm{Cl})$ & & 368 & & 331 & $100.0 \%$ & $0.92[0.73,1.15]$ & & & \\
\hline Total events & 98 & & 99 & & & & & & \\
\hline $\begin{array}{l}\text { Heterogeneity: } \mathrm{Ch}^{2}=1.66, \mathrm{~d} \\
\text { Test for overall effect: } Z=0.7\end{array}$ & $\begin{array}{l}=6(P=0 \\
5(P=0.45\end{array}$ & $95) ; 1^{2}=$ & & & & & $\begin{array}{lll}0.2 & 0.5 & 1 \\
\text { Favours [control] }\end{array}$ & $\begin{array}{l}1 \\
1 \\
\text { Favours }\end{array}$ & 5 \\
\hline
\end{tabular}

Figure 4. Meta-analysis of objective response rate.

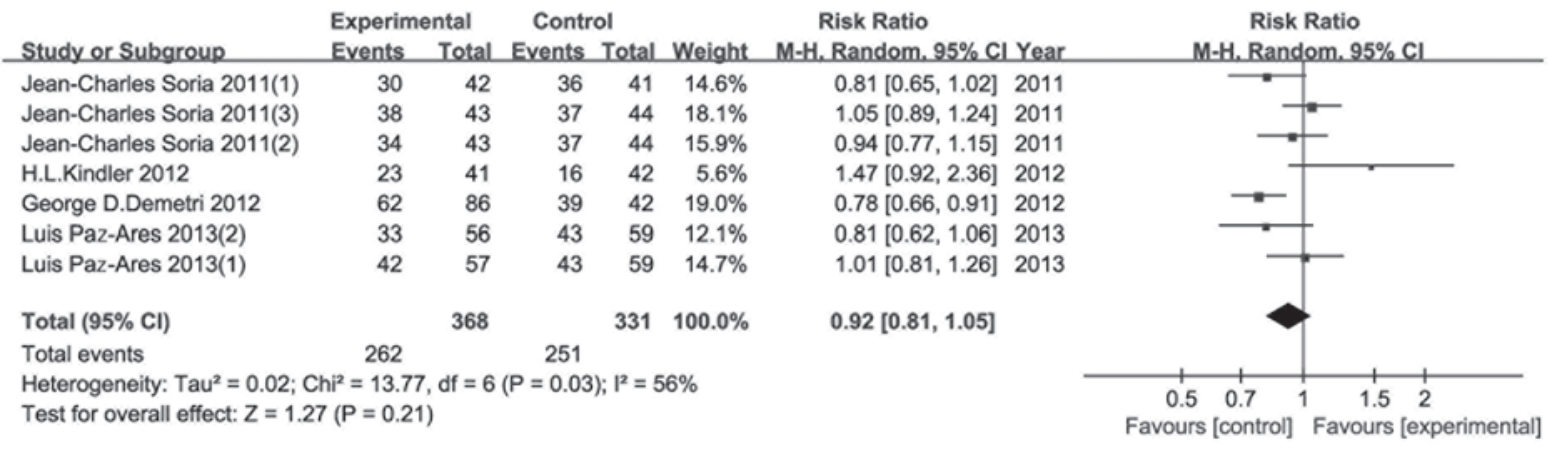

Figure 5. Meta-analysis of clinical benefit rate/disease control rate.

\begin{tabular}{|c|c|c|c|c|c|c|c|c|c|}
\hline Study or Subgroup & \multicolumn{2}{|c|}{ Experimental } & \multicolumn{2}{|c|}{ Control } & \multicolumn{2}{|c|}{ O-E Variance } & \multicolumn{2}{|r|}{ Hazard Ratio } & $\begin{array}{c}\text { Hazard Ratio } \\
\text { Expl(O-E) } / \text { V. Fixed, } 95 \% \mathrm{Cl}\end{array}$ \\
\hline Jean-Charles Soria 2011(2) & 27 & 43 & 30 & 44 & -2.6 & 13.94 & $10.0 \%$ & $0.83[0.49,1.40] 2011$ & \\
\hline Jean-Charles Soria 2011(1) & 32 & 42 & 35 & 41 & -1.81 & 15.53 & $11.1 \%$ & $0.89[0.54,1.46] 2011$ & \\
\hline Jean-Charles Soria 2011(3) & 27 & 43 & 30 & 44 & -1.8 & 14.05 & $10.1 \%$ & $0.88[0.52,1.48] 2011$ & \\
\hline George D.Demetri 2012 & 75 & 86 & 40 & 42 & 3.59 & 25.7 & $18.4 \%$ & $1.15[0.78,1.69] 2012$ & \\
\hline H.L.Kindler 2012 & 38 & 41 & 38 & 42 & -7.49 & 17.38 & $12.4 \%$ & $0.65[0.41,1.04] 2012$ & \\
\hline Luis Paz-Ares 2013(2) & 38 & 55 & 44 & 57 & -2 & 27.58 & $19.8 \%$ & $0.93[0.64,1.35] 2013$ & \\
\hline Luis Paz-Ares 2013(1) & 51 & 57 & 44 & 57 & -4.44 & 25.44 & $18.2 \%$ & $0.84[0.57,1.24] 2013$ & \\
\hline Total $(95 \% \mathrm{Cl})$ & & 367 & & 327 & & & $100.0 \%$ & $0.89[0.75,1.05]$ & \\
\hline Total events & 288 & & 261 & & & & & & \\
\hline $\begin{array}{l}\text { Heterogeneity: } C i^{2}=3.61, d \\
\text { Test for overall effect: } z=1.4\end{array}$ & $\begin{array}{l}f=6(P=0 \\
0(P=0,16\end{array}$ & 73); $1^{2}=$ & $=0 \%$ & & & & & & 0.2 \\
\hline
\end{tabular}

Figure 6. Meta-analysis of progression-free survival.

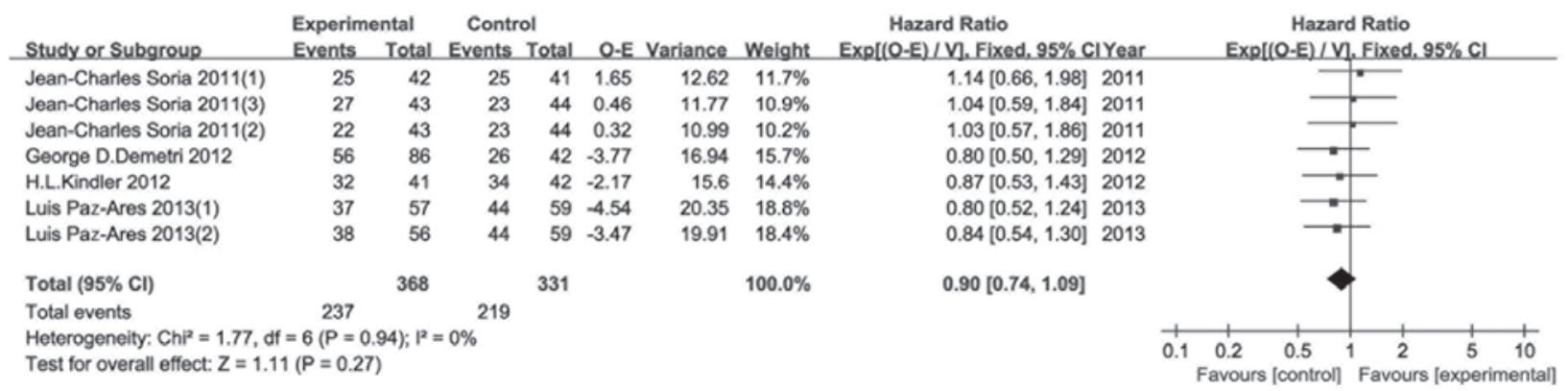

Figure 7. Meta-analysis of overall survival.

results indicated that the addition of TRAIL-related agents conferred no significant benefits to $\mathrm{CBR} / \mathrm{DCR}$ ( $\mathrm{RR}=0.92$, 95\% CI: 0.81-1.05, $\mathrm{P}=0.21)$.
PFS. As the main endpoint of all 4 RCTs, PFS was reported with PFS events, hazard ratio (HR) and $95 \% \mathrm{CI}$. According to the method introduced by Tierney et al (12), 


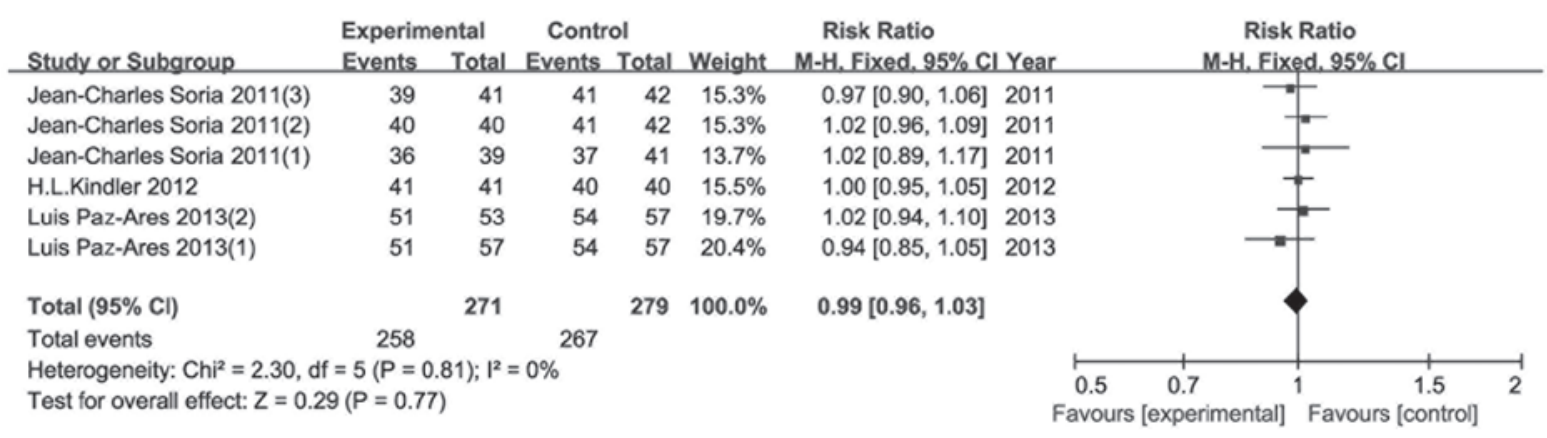

Figure 8. Meta-analysis of patients with any adverse events.

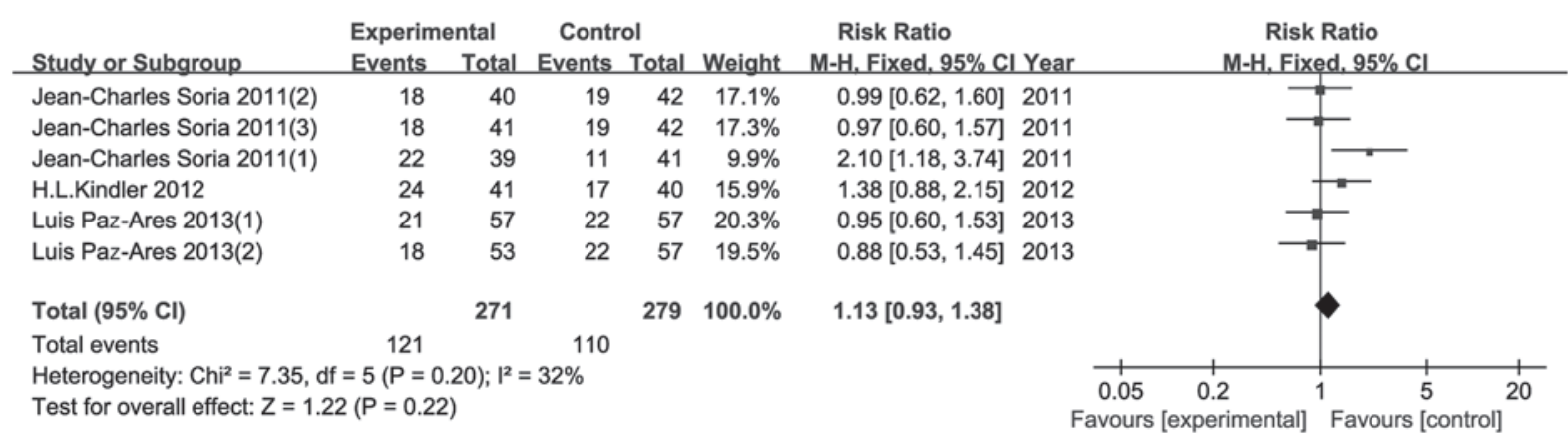

Figure 9. Meta-analysis of patients with any severe adverse events.

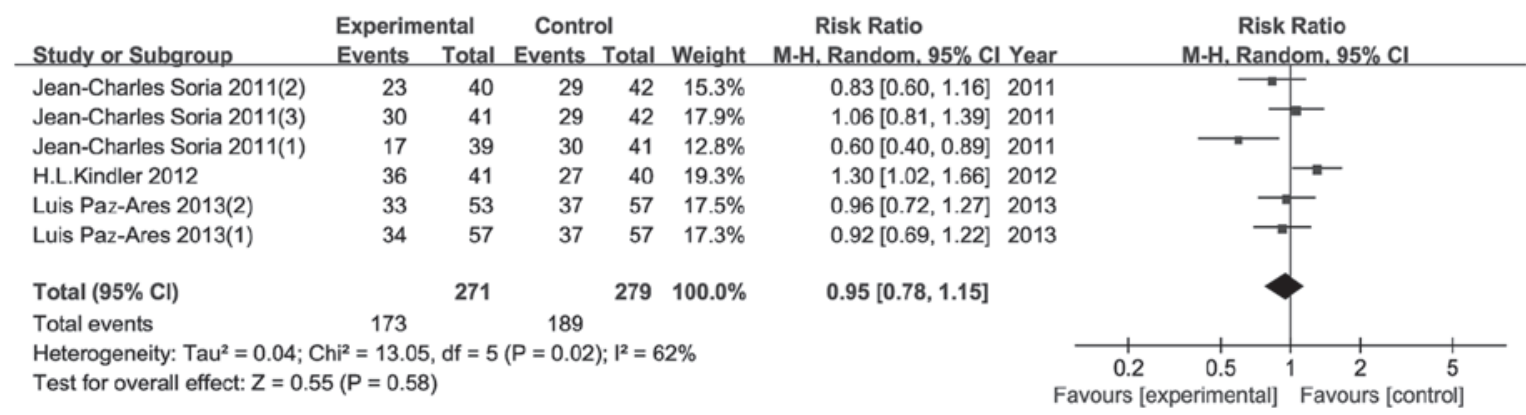

Figure 10. Meta-analysis of patients with $\geq$ grade 3 adverse events.

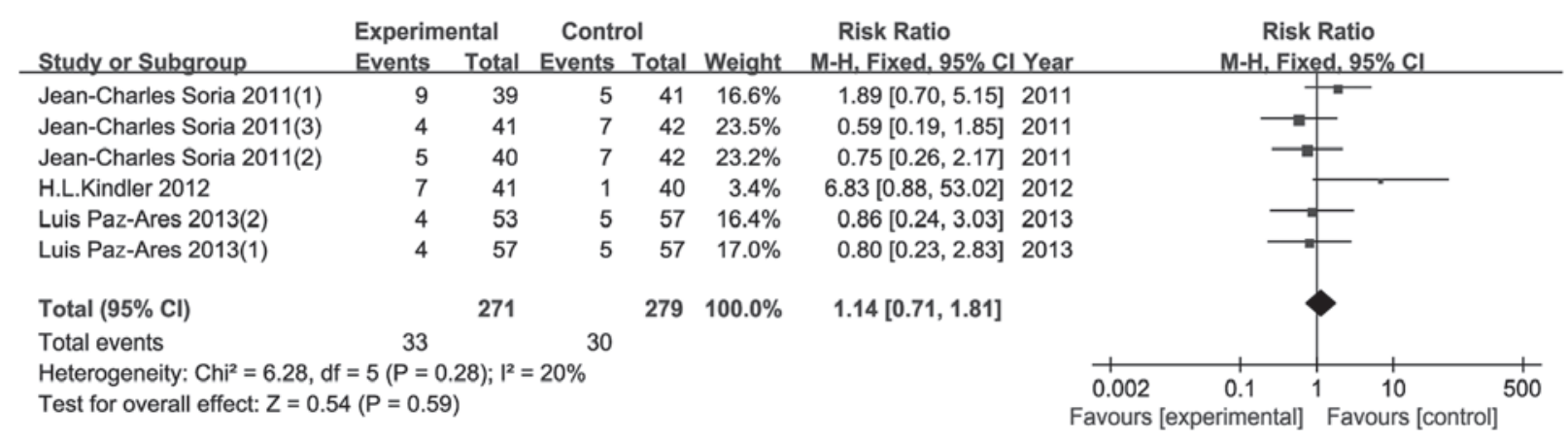

Figure 11. Meta-analysis of fatal adverse events.

we calculated two types of data (O-E and its variance) in this analysis. As shown in Fig. 6, no heterogeneity was observed $\left(\mathrm{P}=0.73, \mathrm{I}^{2}=0 \%\right)$ and a fixed effects model was used. There were no statistically significant differences in
PFS between the experimental and control groups $(\mathrm{HR}=0.89$, 95\% CI: 0.75-1.05, $\mathrm{P}=0.16$ ).

$O S$. The results of the OS meta-analysis are shown in Fig. 7. OS was considered as a secondary endpoint. The 
Table II. Evidence quality and recommendation grade.

Evidence quality assessment

\begin{tabular}{|c|c|c|c|c|c|c|c|c|c|c|}
\hline Outcome & $\begin{array}{l}\text { No. of } \\
\text { studies }\end{array}$ & $\begin{array}{l}\text { Study } \\
\text { design }\end{array}$ & $\begin{array}{l}\text { Risk } \\
\text { of bias }\end{array}$ & Inconsistency & Indirectness & Imprecision & $\begin{array}{l}\text { Publication } \\
\text { bias }\end{array}$ & $\begin{array}{l}\text { Evidence } \\
\text { quality }\end{array}$ & Importance & $\begin{array}{l}\text { Recommendation } \\
\text { grade }\end{array}$ \\
\hline ORR & 4 & $\mathrm{RCT}$ & High $^{a}$ & No & No & No & Undetected & $\begin{array}{c}+++, \\
\text { moderate }\end{array}$ & Critical & Weak \\
\hline CBR & 4 & $\mathrm{RCT}$ & $\operatorname{High}^{\mathrm{a}}$ & No & No & No & Undetected & $\begin{array}{c}+++ \\
\text { moderate }\end{array}$ & Critical & Weak \\
\hline PFS & 4 & RCT & $\operatorname{High}^{\mathrm{a}}$ & No & No & No & Undetected & $\begin{array}{c}+++ \\
\text { moderate }\end{array}$ & Critical & Weak \\
\hline OS & 4 & RCT & High $^{\mathrm{a}}$ & No & No & No & Undetected & $\begin{array}{c}+++ \\
\text { moderate }\end{array}$ & Critical & Weak \\
\hline $\begin{array}{l}\text { Patients } \\
\text { with any } \\
\text { AEs }\end{array}$ & 3 & $\mathrm{RCT}$ & $\operatorname{High}^{\mathrm{a}}$ & No & No & No & Undetected & $\begin{array}{c}+++, \\
\text { moderate }\end{array}$ & Critical & Weak \\
\hline $\begin{array}{l}\text { Patients } \\
\text { with any } \\
\text { severe } \\
\text { AEs }\end{array}$ & 3 & $\mathrm{RCT}$ & $\mathrm{High}^{\mathrm{a}}$ & No & No & No & Undetected & $\begin{array}{c}+++, \\
\text { moderate }\end{array}$ & Critical & Weak \\
\hline $\begin{array}{l}\text { Patients } \\
\text { with } \geq \\
\text { grade } 3 \\
\text { AEs }\end{array}$ & 3 & $\mathrm{RCT}$ & High $^{\mathrm{a}}$ & No & No & No & Undetected & $\begin{array}{c}+++ \\
\text { moderate }\end{array}$ & Critical & Weak \\
\hline $\begin{array}{l}\text { Fatal } \\
\text { AEs }\end{array}$ & 3 & RCT & $\operatorname{High}^{\mathrm{a}}$ & No & No & No & Undetected & $\begin{array}{c}+++, \\
\text { moderate }\end{array}$ & Critical & Weak \\
\hline
\end{tabular}

${ }^{a}$ An open-label study was included. ORR, objective response rate; RCT, randomized controlled trial; CBR, clinical benefit rate; PFS, progression-free survival; OS, overall survival; AEs, adverse events.

Table III. TRAIL-related agents in cancer therapeutics.

\begin{tabular}{|c|c|c|c|}
\hline Reagents & Target & Description & Company \\
\hline rhTRAIL/Apo2L (dulanermin) & DR4/DR5 & rhTRAIL & Amgen $^{\mathrm{a}} /$ Genentech $^{\mathrm{b}}$ \\
\hline HGS-ETR1 (mapatumumab) & DR4 & Fully human MAb & Human Genome Sciences ${ }^{c}$ \\
\hline HGS-ETR2 (lexatumumab) & DR5 & Fully human MAb & Human Genome Sciences ${ }^{c}$ \\
\hline HGS-TR2J (KMTR-2) & DR5 & Fully human MAb & Human Genome Sciences ${ }^{c}$ \\
\hline CS-1008 (TRA-8, tigatuzumab) & DR5 & Humanized mouse MAb & Daiichi Sankyo $^{\mathrm{d}}$ \\
\hline AMG 655 (conatumumab) & DR5 & Fully human MAb & Amgen $^{\mathrm{a}}$ \\
\hline PRO95780 (apomab) & DR5 & Fully human IgG1 MAb & Genetech $^{\mathrm{b}}$ \\
\hline LBY135 & DR5 & Humanized MAb & Novartis ${ }^{\mathrm{e}}$ \\
\hline
\end{tabular}

rhTRAIL, recombinant human tumor necrosis factor-related apoptosis-inducing ligand; DR, death receptor; MAb, monoclonal antibody. ${ }^{a}$ Amgen Inc., Thousnad Oaks, CA, USA; ${ }^{b}$ Genetech Inc., South Francisco, CA, USA; ${ }^{\circ}$ Human Genome Sciences Inc., Rockville, MA, USA; ${ }^{\mathrm{d} D a i i c h i}$ Sankyo Co., Tokyo, Japan; ' Novartis, Basel, Switzerland.

included RCTs reported OS events and HR with 95\% CI, except for one. We then calculated the required data using the abovementioned methods. The fixed effects model was used, as there was no observed heterogeneity $(\mathrm{P}=0.94$, $\left.\mathrm{I}^{2}=0 \%\right)$. There were no notable difference between the experimental and control groups in terms of $\mathrm{OS}(\mathrm{HR}=0.90$, 95\% CI: 0.74-1.09, $\mathrm{P}=0.27$ ).

AEs. As shown in Figs. 8-11, AE data were presented in four parts: i) number of patients with any AEs; ii) number of patients with any severe AEs; iii) number of patients with $\geq$ grade 3 AEs; and iv) fatal AEs. However, Demetri et al (14) presented their results differently and therefore data from that study could not be included in this meta-analysis. There were no significant differences in all four parts between the experimental and the control groups. The risk ratio $(95 \% \mathrm{CI})$ was 0.99 (0.96-1.03, $\mathrm{P}=0.77), 1.13(0.93-1.38, \mathrm{P}=0.22), 0.95$ $(0.78-1.15, \mathrm{P}=0.58)$ and $1.14(0.71-1.81, \mathrm{P}=0.59)$ for $\mathrm{AEs}$, severe AEs, $\geq$ grade 3 AEs and fatal AEs, respectively. 
Sensitivity analysis. A sensitivity analysis was performed by excluding studies one by one. The RRs, HRs, 95\% CIs and P-values for ORR, CBR/DCR, PFS, OS and AEs were similar to the results of the all-set analysis. This indicated that no single study had bias on the results of our meta-analysis.

GRADE assessment. The results of evidence quality and grade of recommendation of the included RCTs are summarized in Table II. There were 8 outcome measures in this analysis: i) ORR; ii) CBR/DCR; iii) PFS; iv) OS; v) number of patients with any AEs; vi) number of patients with any severe AEs; vii) number of patients with $\geq$ grade 3 AEs; and viii) fatal AEs.

\section{Discussion}

Several phase I or II clinical trials assessing the tolerability, pharmacokinetics (13-18), safety and efficacy of TRAIL-related agents for the treatment of cancer patients were conducted from 2004 onwards, reporting that medicines based on TRAIL were tolerable and human anti-TRAIL antibody was rarely detected (13-16). However, the efficacy of TRAIL-related agents was not found to be satisfactory. The TRAIL-based agents that were previously used in clinical trials are summarized in Table III.

ORR was the main outcome in the majority of stage II/III clinical trials. The number of patients with $\mathrm{CR}$ and $\mathrm{PR}$ reflected the efficacy of chemotherapy. In our analysis, we failed to demonstrate substantial evidence supporting the addition of TRAIL-related agents to first-line treatments for cancer ( RR=0.92,95\% CI: 0.73-1.15, P=0.45). However, our study had certain limitations, which are discussed below. CBR was also used as an index of efficacy. The number of patients with SD did not affect our results. The median heterogeneity may be a result of the different types of cancer and treatment. Although the included RCTs had recruited patients with advanced-stage cancer, different types of cancer exhibit differences in chemosensitivity.

Survival data were analyzed using the methods described by Tierney et al (12). The results of PFS and OS indicated that the addition of TRAIL-related agents conferred no significant benefits to the patients. Furthermore, there was a tendency in favour of the control groups, suggesting that the addition of TRAIL-related agents should be avoided. The patients who were lost during follow-up were $\leq 10 \%$ of the total patients and the results of the survival analysis were considered to be reliable. However, the method applied for this data type was not accurate, particularly the O-E and variance of OS from the Kindler et al study (15), which were estimated from the survival curve using Engauge Digitizer 4.1 software. This lack of accuracy may result in bias.

We also assessed AEs as an endpoint. The common AEs included nausea, alopecia, fatigue, dyspnea, anemia and neutropenia. The majority of the AEs were not associated with the administration of TRAIL-related agents. Although we did not detect a significant difference in this analysis, we consider the data to be reliable. Furthermore, patients with advanced cancer tolerated TRAIL-related agents well, which is consistent with the results of the majority of the phase I clinical trials (13-18).
There were several limitations to this study. First, the meta-analysis was limited to articles published in English, leading to a selection bias in language. Second, the control groups from 2 studies were used twice, which may enhance the effect of the control group. Third, the total number of patients was limited and all patients were diagnosed with advanced-stage cancer; therefore, the prognosis was worse compared to that of patients with early-stage cancer, which may have masked the effects of TRAIL-related agents. Moreover, the 4 included RCTs experimented on different types of cancer and treatment strategies and we had to overlook the differences among them in order to gain preliminary results on this topic. Finally, the treatment cost was not taken into consideration; this, however, is a factor that may affect the patients' perspective regarding this type of treatment.

In conclusion, this meta-analysis compared the outcome of patients with advanced cancer who were treated with or without TRAIL-related agents. There were no significant differences in all 8 outcome measures, including ORR, CBR/DCR, PFS, OS, number of patients with any AEs, number of patients with any severe AEs, number of patients with $\geq$ grade 3 AEs and fatal AEs. Therefore, the benefits of the addition of TRAIL-related agents to standard chemotherapy regimens for the treatment of cancer patients remain uncertain.

\section{Acknowledgements}

This study was supported by grants from the National Nature Science Foundation of China (grant no. 81071908).

\section{References}

1. Siegel R, Naishadham D and Jemal A: Cancer statistics, 2012. CA Cancer J Clin 62: 10-29, 2012.

2. Wiley SR, Schooley K, Smolak PJ, et al: Identification and characterization of a new member of the TNF family that induces apoptosis. Immunity 3: 673-682, 1995

3. Pitti RM, Marsters SA, Ruppert S, et al: Induction of apoptosis by Apo-2 ligand, a new member of the tumor necrosis factor cytokine family. J Biol Chem 271: 12687-12690, 1996.

4. Pan G, O'Rourke K, Chinnaiyan AM, et al: The receptor for the cytotoxic ligand TRAIL. Science 276: 111-113, 1997.

5. Pan G, Ni J, Wei YF, et al: An antagonist decoy receptor and a death domain-containing receptor for TRAIL. Science 277: 815-818, 1997.

6. Rowinsky EK: Targeted induction of apoptosis in cancer management: the emerging role of tumor necrosis factor-related apoptosis-inducing ligand receptor activating agents. J Clin Oncol 23: 9394-9407, 2005

7. Marsters SA, Sheridan JP, Pitti RM, et al: A novel receptor for Apo2L/TRAIL contains a truncated death domain. Curr Biol 7: 1003-1006, 1997.

8. Ashkenazi A, Holland P and Eckhardt SG: Ligand-based targeting of apoptosis in cancer: the potential of recombinant human apoptosis ligand 2/tumor necrosis factor-related apoptosis-inducing ligand (rhApo2L/TRAIL). J Clin Oncol 26: 3621-3630, 2008.

9. Bellail AC, Qi L, Mulligan P, et al: TRAIL agonists on clinical trials for cancer therapy: the promises and the challenges. Rev Recent Clin Trials 4: 34-41, 2009.

10. Higgins JPT, Green S (eds). Cochrane Handbook for Systematic Reviews of Interventions Version 5.1.0. The Cochrane Collaboration, 2011. www.cochrane-handbook.org. Accessed, September 20, 2013.

11. Schunemann H, Brozek J and Oxman A (eds): GRADE handbook for grading the quality of evidence and the strength of recommendations. Version 3.2 (updated March 2009). GRADE Working Group, 2009. Available from http://www.cc-ims.net/gradepro. Accessed, September 20, 2013. 
12. Tierney JF, Stewart LA, Ghersi D, et al: Practical methods for incorporating summary time-to-event data into meta-analysis. Trials 8: 16, 2007

13. Soria JC, Mark Z, Zatloukal P, et al: Randomized phase II study of dulanermin in combination with paclitaxel, carboplatin, and bevacizumab in advanced non-small-cell lung cancer. J Clin Oncol 29: 4442-4451, 2011.

14. Demetri GD, Le Cesne A, Chawla SP, et al: First-line treatment of metastatic or locally advanced unresectable soft tissue sarcomas with conatumumab in combination with doxorubicin or doxorubicin alone: a phase I/II open-label and double-blind study. Eur J Cancer 48: 547-563, 2012.

15. Kindler HL, Richards DA, Garbo LE, et al: A randomized, placebo-controlled phase 2 study of ganitumab (AMG 479) or conatumumab (AMG 655) in combination with gemcitabine in patients with metastatic pancreatic cancer. Ann Oncol 23: 2834-2842, 2012.
16. Paz-Ares L, Balint B, de Boer $\mathrm{RH}$, et al: A randomized phase 2 study of paclitaxel and carboplatin with or without conatumumab for first-line treatment of advanced non-small-cell lung cancer. J Thorac Oncol 8: 329-337, 2013.

17. Plummer R, Attard G, Pacey S, et al: Phase 1 and pharmacokinetic study of lexatumumab in patients with advanced cancers. Clin Cancer Res 13: 6187-6194, 2007.

18. Tolcher A W, Mita M, Meropol N J, et al: Phase I pharmacokinetic and biologic correlative study of mapatumumab, a fully human monoclonal antibody with agonist activity to tumor necrosis factor-related apoptosis-inducing ligand receptor-1. J Clin Oncol 25: 1390-1396, 2007. 